Southern Illinois University Edwardsville SPARK

SIUE Faculty Research, Scholarship, and Creative Activity

2018

\title{
A Model of Transcorporeal Communication: Communication toward/with/to the Deceased
}

Jocelyn M. DeGroot

Southern Illinois University Edwardsville, jocbrow@siue.edu

Follow this and additional works at: https://spark.siue.edu/siue_fac

Part of the Communication Technology and New Media Commons, and the Interpersonal and Small Group Communication Commons

\section{Recommended Citation}

DeGroot, J. M. (2018). Communication to/with/toward the deceased: A model of transcorporeal communication. OMEGA: Journal of Death and Dying, 78(1), 43-66. doi:10.1177/00302281683195

This Article is brought to you for free and open access by SPARK. It has been accepted for inclusion in SIUE Faculty Research, Scholarship, and Creative Activity by an authorized administrator of SPARK. For more information, please contact magrase@siue.edu. 
A Model of Transcorporeal Communication: Communication toward/with/to the Deceased

Jocelyn M. DeGroot

Southern Illinois University Edwardsville

Author Note

Jocelyn M. DeGroot, Department of Applied Communication Studies, Southern Illinois University Edwardsville.

The author would like to thank Heather Carmack for her insightful comments on this manuscript.

Correspondence concerning this article should be addressed to Jocelyn DeGroot, Department of Applied Communication Studies, Box 1772, Southern Illinois University Edwardsville, Edwardsville, IL 62026, 618-650-5828. Email: jocbrow@ siue.edu 


\begin{abstract}
Research indicates that people maintain a connection with deceased loved ones, which can be healthy for the bereaved individuals. To maintain these bonds, people readily admit to communicating with the deceased. Although communication with the deceased shares similarities with traditional models of interpersonal communication, it is distinctly different. Interviews with 20 individuals revealed support for a model of Transcorporeal Communication (TcC), communication to people who do not maintain a physical presence. This communication includes the components of sender, inner-representation of the deceased as receiver, message, feedback based on what the sender believes the deceased would say, and a metaphysical element. Implications of TcC for griefwork are also discussed.

Keywords: transcorporeal communication, grief, communication model, deceased, continuing bonds
\end{abstract}


Complete disengagement from deceased loved ones was previously the end goal of mourning (Hofer, 1984; Rando, 1986; Raphael, 1983). Attempts to maintain a relationship with the deceased was deemed a psychological concern that should be actively avoided or remedied (Jackson, 1957). Raphael (1983) and Rando (1992) argued that survivors should move toward a future that does not include the deceased as an active "participant" in reality. Field, Nichols, Holen, and Horowitz (1999) discussed potential negative repercussions of continuing communication with the deceased (e.g., avoiding attachments with others, inhibiting grief resolution, psychological distress). Research has since thoroughly investigated and established the continuing bonds that exist post-death and can be healthy for the bereaved (Attig, 1996, 2001; Glick, Weiss, \& Parkes, 1974; Hallam, Hockey, \& Howarth, 1999; Mitchell, 2007; Schuchter \& Zisook, 1993). Rubin (1985) identified a correlation between the ability to relate to an inner representation of the deceased and ability to cope with the loss. In fact, an entire edited volume on continued bonds with the deceased (Klass, Silverman, \& Nickman, 1996) was published, in which scholars from a variety of disciplines advocated for maintaining a connection to a deceased loved one.

To maintain these bonds, people readily admit to communicating with their deceased loved ones (DeGroot, 2012; Field, Gal-Oz, \& Bonanno 2003; Glick et al., 1974; Klass \& Walter, 2001; Parkes, 1970; Rees, 1971; Shuchter \& Zisook, 1993). However, the distinctive model of communication used by the living as they talk to their deceased loved ones has not been assessed in prior research. The current study relies on interviews with people who talk to deceased loved ones to identify and provide support for a model of Transcorporeal Communication (TcC). Trans indicates that the communication occurs in a different state or beyond a certain state, and corporeal indicates a relationship to a physical material body. As deceased people no longer 
maintain a physical presence, messages to the deceased are directed at someone who is in a different state of being physically present. It is this communication that is recognized and explicated.

\section{Continuing Bonds with the Deceased Through Communication}

Numerous researchers have advocated for the continuance of bonds after a loved one has died (Attig, 1996, 2001; Glick et al., 1974; Hallam et al., 1999; Mitchell, 2007; Schuchter \& Zisook, 1993). Many people continue to engage in meaningful social relationships with their deceased loved one. Maintaining these bonds with the dead requires the use of a unique form of communication with the deceased in order to uphold the relationship. The notions of (a) continuing bonds with, (b) an inner representation of, and (c) communication to the deceased are vital components toward understanding the specifics of the unique communication that occurs as the living communicate to the deceased.

\section{Inner Representation of the Deceased}

People often create "inner representations" of the deceased when struggling to maintain a relationship with them following the loved one's death. As a result, the deceased's presence often continues in a psychological sense as well as in a social sense, as the deceased continue to exercise agency within the living's existence (Marwit \& Klass, 1994-1995). Sensing a presence, considering the deceased to have a continuing influence on one's life, or purposefully incorporating the deceased's characteristics or morals into one's own self indicates interaction with one's inner representation of a deceased loved one (Fairbairn, 1952; Marwit \& Klass, 19941995). Fairbairn (1952) first described the "inner representation" as aspects of the self that are identified with the deceased, memories or characteristics of the deceased, and emotional conditions that are connected with memories of the deceased. Silverman and Klass (1996) 
explained, "Survivors construct a sense of the deceased and develop an inner representation of that person." (p. 19). It is with this presence that the grieving individuals interact and communicate. The inner representations offer guidance, are role models, help clarify values, and exist in memories (Klass, 1993; Marwit \& Klass, 1994-1995).

\section{Communication to the Deceased}

Communication to the dead is common. Mitchell (2007) emphasized the notion that social interaction does not end simply because someone is not physically present. As discovered in numerous studies, many people sense the presence of the dead and consider conversations with them to be meaningful (Glick et al., 1974; Klass \& Walter, 2001; Parkes, 1970; Rees, 1971; Shuchter \& Zisook, 1993). De Vries (2001) described communication to the dead:

Many individuals report ongoing communication with the deceased at just such daily junctures. This is not just the stuff of séances or extrasensory experiences; it is a sort of "checking in" and wondering what the deceased would think or do at a particular occasion. (p. 76)

Field et al. (2003) found that widows often imagine their deceased loved ones and "connect" with them through imagined interactions. These conversations can help the living confront the loss and adjust to life without their loved one, which Stroebe and Schut (1999) argued is an important part of grieving. Hastings, Hoover, and Musambira (2005) agreed and found that messages to the deceased are cathartic, and maintaining a connection with the deceased can be a beneficial, healthy part of bereavement. More recently, research has focused on the online communication (e.g., via social media posts) to the deceased (Brubaker \& Hayes, 2011; DeGroot, 2012; Egnoto, Sirianni, Ortega, \& Stefanone, 2014; Hastings et al., 2005; Pennington, 2013). 
People communicate to the deceased for various reasons. Often, in order to live without the physical presence of their deceased friend or family member, people try to continue with their lives as normally as possible (Attig, 2001). Part of maintaining one's normal routine can include talking with the deceased as he or she did before the death, exhibiting relational continuity. People essentially struggle to develop an identity where the deceased is now part of the past self and not the present self (Davis, Nolen-Hoeksema, \& Larson, 1998; Weiss, 1993), and communicating with the deceased appears to ease the transition.

It appears that the communication occurring between the living and the deceased is a unique type of communication. Results from the current study empirically illustrate a type of communication that has not yet been closely examined. Communication scholars have focused primarily on the transactional model of communication while disregarding a model of communication in which there is absolutely no opportunity for observed receiver feedback yet a distinct intended receiver exists. I focus my efforts on re-examining this type of communication and discovering its implications.

\section{Research Questions}

Previous research has demonstrated that people communicate with their deceased loved ones in order to make sense of the death as well as continue bonds with the deceased (Attig, 1996, 2001; DeGroot, 2012; Glick et al., 1974; Hallam et al., 1999; Mitchell, 2007; Schuchter \& Zisook, 1993). Subsequent research provided a brief examination of this type of communication (DeGroot, 2012). The purpose of the current study was to more extensively explore the specific type of communication utilized in post-death communication and establish a model of that communication. To investigate this type of communication, I posed the following research questions: 
RQ1: How do people characterize their communication to the deceased?

RQ2: How does this type of communication differ from traditional models of communication?

Interviews with people who talk to their deceased loved ones were utilized in order to respond to these research questions and explore people's communication toward the deceased.

\section{Method}

To gain a better understanding and description of the type of communication occurring between the living and the deceased, I conducted Skype and email interviews (depending on the participant's preference) with 20 individuals.

\section{Participants}

To recruit participants for my study, I posted a call for participants on my social media profiles as well as reaching out to friends, family, and acquaintances who might know of additional participants (i.e., "snowball” method; Biernacki \& Waldorf, 1981). I sought people who identify as talking to a deceased loved one. I specifically noted that I was not focusing on the communication that psychics or mediums may utilize. From here, participants decided on a Skype interview or an email interview based on their schedules and preferences. That is, some were more comfortable disclosing information about their communication with their deceased loved ones in an asynchronous email rather than a synchronous face-to-face Skype interview.

Five men and 15 women participated in the interviews, ranging in age from 19-67 years old $(M=39.15, S D=15.04)$. Five of them identified as spiritual, 10 identified as religious, 2 were both religious and spiritual, and 3 were not religious nor spiritual. In the interviews, participants generally focused on their communication with one deceased person; two participants focused on two people. The deceased consisted of 13 men and 9 women. Their mean 
age was 50.09 years (range 0-97 years; $S D=29.42$ ), and the time passed since the death ranged from 1 month to 26 years $(M=6.92 ; S D$ 6.9). The causes of death were varied and included cancer, heart attacks, accidents, and health complications. Although the participants' mental status was not assessed nor potential psychiatric diagnosis identified, all participants appeared to be experiencing a healthy mourning period. Table 1 further details information about the participants and the deceased.

\author{
*Insert Table 1 here*
}

\title{
Interviews
}

Prior to each interview, I individually emailed each participant a consent form to read and agree to by responding to the initial email. After consent was given, we either set up a time for a Skype interview, or I emailed the interview questions to the participant. Participants were asked questions regarding their relationship and communication with the deceased before and after the death. The same questions were asked in both interview formats. Seven Skype interviews were recorded and transcribed. At the end of the Skype interviews, I showed participants an initial version of the communication model being utilized as people talked with their deceased loved ones to elicit feedback. Additionally, 13 email interviews were conducted. I also sent email participants follow-up questions as well as a pdf of the initial communication model and asked for feedback. After minor adjustments to the model in response to participant comments, I again conducted member checks (Lincoln \& Guba, 1985), which indicated a strong affirmation of the revised model (see Figure 1). This model is further explicated below. The type of interview conducted (i.e., Skype or email) did not appear to have an effect on the content or quality of the interview responses. 
Exploration of the information gleaned from the interviews included a thematic analysis that initially focused on the principle components of communication with the deceased identified in previous research (DeGroot, 2012), which resulted in a thorough depiction of each component (with examples) discussed in the results section. Particular attention was paid to elements mentioned by participants that were not present in the initial hypothesized version of the TcC model (DeGroot, 2009). These are also discussed.

\section{Results}

Results generally supported the initial model of $\mathrm{TcC}$, which included the sender, message, channel, content, inner-representation of the deceased as receiver, and feedback based on what the living thought the deceased would say. Additionally, participants indicated the need to identify a trigger, something that prompts them to talk to the deceased. Interviewees also noted the absence of "an unexplained other," which was then labeled as the metaphysical component. Figure 1 illustrates the updated model of transcorporeal communication. Each component of the model is described below.

*Insert Figure 1 here*

\section{Sender}

By creating and transmitting messages, this study's 20 participants displayed what it means to be a sender in TcC. Differences in the participants' age, gender, employment, and education did not appear to have a noticeable effect on how their communication manifested. As such, in this communication model, the sender is any person who maintains a connection with the deceased by communicating to him or her.

\section{Message}


The message in TcC includes what is said, the context in which it is said, and the medium used to send it. When describing the communication utilized when talking to the deceased, many people identified it as "one-sided," "less transactive," or "an illusion," revealing an interesting tension between one-sided conversations that are still considered as conversations (typically requiring two active people). Although participants acknowledged this one-sided nature of the communication with the deceased (without an active message recipient), they also indicated a distinct feeling that this communication does not occur in a purely closed system. One person explained, “The [Facebook] messaging is simple conversations. Even though it's one-sided, it still feels like conversations." Another said, "I know it is more one-sided, but I feel he hears me and I draw comfort from that." Others insisted that nothing had changed in their communication and relationship other than the absence of a physical presence. For example, "Obviously the lack of physical contact or togetherness [has changed since the death], but honestly not much has changed in the conversations that I have with my father." She continued, "I have like a conversation with him like I would have a conversation with you."

One person aptly described the communication between her and her deceased grandfather: "Sometimes it seems a little one-sided but I don't think it is. I don't know. It's weird and I don't pretend to understand it. But it's nice." Another person compared this type of communication to "living someplace that you don't have any internet and you've got really shoddy phone service but someday you're going to go back and you're gonna catch up."

Many of the interviewees indicated the "normalness" of this type of communication. One person said, "I would actually be more surprised if there were people who didn't talk to their loved ones." A participant who lost his brother explained why he talks to him, "I know there's still an emotional attachment there. That's why I have the conversations that I do. It's not from 
an aspect of sadness." The participant continued by comparing this feeling to a "phantom limb: a conversation I'm having with something that isn't there."

Channel. The channel of communication used by the living to talk with the deceased generally fell into one of three categories: spoken aloud, written or typed, or internal. The channel used was typically governed by the participant's location and privacy. People tended to speak out loud to the deceased at the cemetery, in a car, toward an urn, or when talking to a photograph. This generally happened when the person was alone. Written communication intended for the deceased included typed letters, handwritten notes, public Facebook posts, private Facebook messages, emails, and texts. The final channel used was internal or, as many participants described it, "in my head."

The channel of communication employed by the living appeared to depend on the importance of the message topic. For example, one participant revealed that he will intentionally travel to the cemetery to tell his mother about important milestones:

But you know when a significant life event occurs, I will usually make a trip - the cemetery is in [town], so it's a little ways away, but I'll make a trip down there and share that news. When I finished my dissertation defense, I went right there that was my first stop - to the cemetery to you know...share that news with my mom.

Content. Interviewees indicated that their messages consisted of general updates, stories, requests for help, bereavement, regrets, and some anger. Topics ranged from the mundane to the truly affective. Message content appeared to parallel the content in online messages to the deceased found in earlier research (DeGroot, 2012). One person explained the topic of her letters to her deceased friend as "more or less what I have been up to. Things going on in my life, or random memories that come and go from time to time." Another participant explained what she 
talks to her grandfather about: "It's kind of like having him as a confidant in a weird way....Just this is what happened or boy things really suck right now or hey look at this. Check this out. I met this guy.” Many participants admitted to asking their deceased loved ones for help or for guidance. For example,

I'm not Catholic but in Catholicism you pray to the saints to ask for intercession. Sometimes I do that with him too. It's like "Hey can you like put a word in for me? I'm not sure He's hearing me right now."

Another participant said, "So I would say to him, 'Sweetie it's really hard for Mom. I'm really struggling. It'd really help me if you would just give me a reason to go on."' In another example, a participant explained why his messages are often those of requests for guidance: "I've always leaned on my mom for that type of supportive communication when we would talk or speak when she was alive. And so I'm still - I'm seeking that from her."

One person said that her messages sometimes include: "admitting to him what I wished I did more of or different while he was alive. Regrets." One woman said many of her conversations with her recently deceased husband centered on "anger that he is not here, that he left me." Another recent widow agreed: "I talk to him quite a bit telling telling him about the daily occurrences and alternate between cussing him out for leaving me with such a mess." The variety in content suggests that TcC could be a "normal" communication experience (i.e., focused on everyday, mundane topics) or could be more emotionally-based, triggered by something visceral.

Trigger. Messages to the deceased were prompted by something, a trigger, such as a photo or an event. While each participant had a different set of communication triggers, there was always something that initiated the conversation. These triggers ranged from the positive to 
more anxiety-related. Positive triggers included the living person seeing something the deceased would like or find humorous, reaching a "milestone," or when reminded of the deceased by something in the environment.

A participant explained that he talks to his mom, "whenever I think of something funny that I know she would appreciate." Another said, "Speaking to her is something that just happens when I feel the need to do so, particularly if I experience something that I know she would find amusing.” Important milestones that were triggers included getting married, having children, and graduating from college.

Others are triggered by something physical in the environment. Sometimes the trigger was a tangible object, such as a particular photograph in the participant's house, pictures of the deceased that showed up on a Facebook newsfeed, or seeing the deceased's urn. One participant explained, "Occasionally I will tell her that I miss her. For the most part, this only occurs when I am passing by or directly walk to the picture I have of her hanging in a frame on my kitchen wall.” A participant who had lost her son explained one of her triggers:

And we're driving along and I look over and there's a boy who didn't look anything like my son but the young boy sitting there eating a foot-long hotdog on the street. Just eating a hotdog. And there was a hotdog stand. And I was just flooded with this memory. I just started crying and in my mind I was talking to Rourke because he went through a period of about three years where his favorite food in the world was foot-long hotdogs.

People also indicated communication triggers that were present in times of distress. They would need help, ask for advice, or request guidance during a tough period in their lives. For example, "Sometimes when I hit a depressive state, it's almost like 'Hey grandpa. Shout out to you!' Like 'Help me a little bit here." Another person agreed, "I often times think of my mom 
and if I've got something big happening or I'm struggling with something, I'll ask for a little bit of guidance and support."

The trigger itself appeared to be clearly connected to the message content (e.g., mundane, affective). That is, a mundane trigger would initiate a typical, non-emotive message.

Evolution of communication. The communication between the living and the deceased appeared to evolve in terms of frequency, channel, and content as more time passed. There was sometimes a reduction in frequency and intimacy. The frequency of communication decreased for many people. For example,

I still feel close to my grandma and I visit her often. At first, I visited her every day because her cemetery is right by [work] and I would drive by every day and stop to say hi. I visit her now about once a week and make sure that her flowers look the way that I like them too.

One woman detailed how her communication with her deceased mother has changed:

When she first died I spoke to her often. When I was old enough to drive I would often go to her gravesite and speak to her. When I moved away to college and could no longer visit the cemetery, I started writing letters to her. Now that I'm older, my communication to my mom is more like meditation. I don't usually speak out loud, and it's usually when I need to re-center or wish that I could call her or curl up in her arms.

Another person explained how the content and intimacy of the messages changed, "My communication when she first passed away was very personal and sentimental. Now, it is more generic, such as 'Happy Birthday' or 'Thinking of you today!'”

\section{Intended Recipient}


All interviewees had an intended addressee of their messages. Sometimes the intended recipient was an inner-representation of the deceased (as described by Marwit \& Klass, 19941995). In other instances, the communication was directed at an object that represented the deceased (e.g., urn or cemetery plot) or photograph of the deceased, but the deceased was still visualized. Further, the relationship between the living and the dead appeared to mimic the relationship before the death.

Inner-representation of the deceased. Many people said they picture the deceased in their minds when talking to them. In most cases, they envisioned the "healthy-looking" version of the deceased, and this version of the deceased does not age for the participants. Descriptions of the representation were incredibly detailed. One description read,

She looks like she always did. I see her. I see her smile. I see her nodding and listening just like she would have done when she was alive. She doesn't age. The image of her is not necessarily an image of her being sick. It's usually an image of her before she really got very ill. A positive. I think that's what you want to remember.

Another person agreed, 'It's not who she was in the end, it's who she was about 7 years ago. It's grandma when she could still walk around, she could still cook, and she could still hold a nice conversation." One participant explained why she thought her deceased son does not age, "For me he's still thirteen. Now the reason I actually think they don't age, not that I'm a theologian, is if they age, there' $d$ be people in heaven that are like 3000 years old [laughter]. And that's hard to picture!" One participant indicated he did not necessarily visualize his mother when talking to her, but he went on to explain,

Part of the reason is because the mental images that are in my head are all of her dying. And that's what I'm stuck with because she was dying for such a long time and she 
looked like crap. She was bald. She was bloated and then she was shriveled. When I even think about it now, that's the image that pops into my head. And so mostly I hear her. I don't see her because the visions that I have don't line up with who I remember...And it drove her nuts that she didn't look the way she wanted to look. It feels somehow disloyal to think about her that way.

Some participants revealed that they often pictured where the deceased would be proximally located. For example, “And I'll picture him like sitting next to me. Like I'm driving with him.” Another explained, "It's more like he's standing there. The example I have is like when he was still well, we went to ballgames. We enjoyed those. So side-by-side. So we were in the seats talking to one-another."

Relational continuity. The primary theme that emerged as participants described their communication with the deceased was the clear intent that this communication is meant to keep the deceased "alive" in a sense. Relational continuity was a primary concern for everyone. People said they could still feel the deceased's presence and his or her love. One woman said, I like feel him - his presence. And I don't know. I stopped being concerned whether it's real or not. Just those feelings that we have inside that are so strong that they communicate things to us that enable us to structure our reality. That's how this is to me. It just feels real for me. And I don't even care if other people don't see it. Another participant said, "I feel like I talk to her as much now as I ever did. I might even talk to her more. I love her just as much as ever." A woman who lost her mother disclosed, "I still talk to her in the same way I used to 19 years ago-openly and honestly. I feel that if she were to come back, we would hardly skip a beat in our relationship." One participant continues to use his mother's handwritten recipe cards and admitted to, in a sense, "cooking" with his 
mother. He remarked, “And I always stop and think 'What do you think, mom? You'd have done this right?' So that's very much a point of connection that carries over."

Many participants said they still love the deceased and want to keep his or her memory alive. One wrote, "[The relationship] is going good. We have a lot of family and friends who tell stories, talk about him and keep him 'alive.' It makes everything easier having so many people still discuss him." Another felt obligated to continue the communication: "I almost feel a responsibility to keep posting to her Facebook so that I don't forget about her."

One participant did indicate a strained relationship with the deceased due to pressure from other friends to stop communicating with the deceased:

I feel some pressure from other friends of mine that knew her that I should be over it by now. So talking to her, crying about her, or visiting her grave is pretty stressful, because I feel that emotionally, I should be over it by now, even though I'm not.

\section{"Feedback"}

After sending messages to the deceased, often, the participants would give themselves feedback based on what they think the deceased would do or say. Feedback presented itself both verbally (e.g., hearing a message) and nonverbally (e.g., signs and feelings). When the response was verbal, some participants said they could actually hear the deceased's voice. A participant explained, “I'm almost imagining I hear his voice. I'm just imagining the way that he speaks. Even though it's imagined, right - I'm trying to imagine him as he was. The sound of his voice. His mannerisms." Another person described, "I'd get in my car to someplace and he'd be like, 'remember the speed limit is 55!' I can hear him talking sometimes too. But mostly it's the stuff I've known him to say." For the most part, participants admitted that the responses received 
"from" the deceased were always in line with their viewpoint when alive, and the phrases they hear are usually phrases that the deceased said when alive. For example,

Sometimes I can actually hear his voice saying something that I never heard him say in reality, but that is something he would say about that thing I'm thinking about. It represents kind of his thinking or philosophy. Everything I think I hear him say or just a feeling he gives me is consistent with what I knew of him when he was here. Like there are no inconsistencies.

When asked to describe the process of getting a response during this type of communication, one person explained, "I guess I ask myself how she would respond in certain types of situations, or I go back to some of the last conversations that we had and replay them in my head." Other participants agreed, "I still rely on my dad for advice, and think it through in a frameset of what he would do." Another said, "She is predictable in the kinds of things that I imagine her saying." Participants were relatively pragmatic in their understanding of how the feedback functioned,

Sometimes it's a simple confirmation of what I was thinking (I would guess that comes from my subconscious). Sometimes it something he may have said in the past. Sometimes it may be something new, but again I have enough skeptic in me to rationalize that to subconscious meanderings.

Others further tried to explain how they believe this feedback is generated. For example, I'm going through my own mental Rolodex and trying to remember how he would respond. And I think I'm filling in the blanks. It's sort of like a weird game of Mad Libs where I have the questions answered and it's magically filling in the answers. 
Another person explained, "You know in a lot of ways it's almost like these algorithmic music composition programs that once you know how Beethoven wrote music, you can program a computer to write new Beethoven music." One participant revealed that she views the process as, "recollecting the past co-construction and kind of using that to fill in the information with what makes rational sense to me. But instead of it being wishful thinking, it feels even more real because it's based on data."

While some people reported getting "verbalized" feedback, others described getting a more nonverbal type of feedback through seeing signs or having feelings of presence. Signs perceived by the living included anything from special numbers, songs, animals, and pennies and were viewed as a form of indirect feedback or as an indicator of their presence. One woman explained, "I think she sends me signs to let me know that things are okay. I tend to see her in butterflies, hummingbirds, and rabbits which are all things she loved."

Some participants experienced feelings or sensations they attributed to the deceased's presence or thoughts toward something. For example, "I talk to him about something and then I experience this feeling that he wouldn't want me to be sad. Or that he would want me to be comfortable with whatever decision I make." Another agreed, "So in the nonverbal sense I guess that is his response to me, helping me out and calming me down." One man described that he views signs as responses from his mom,

Since my mom's passing, I very much have become aware of signs and signals that maybe don't normally exist. It's not like I hear her voice in my head saying “yes” but then something will happen. So I think for me, I internalize that as a recognition of her presence and a form of communication. 
Some participants indicated that they do not receive feedback from the deceased. However, in these instances, the lack of feedback was actually similar to the deceased's communication when he or she was alive. A widow described the current communication with her deceased husband, "Communication is one way, but then I think he tuned me out a lot, too, so it's probably not so different! He just let me rant and tried to make me see how far off base I was." Another participant indicated that he does not expect a response from his deceased mother, but then explained, "I have an expectation that I have requested this, you are the mother figure, you will fulfill this. I maybe am asking too much of her now that you phrased it that way! [laughs]"

Although most study participants described getting feedback in conversations with the deceased, many balked at using the term "feedback" to describe the responses to their communication to the deceased. Some participants indicated that they do not get feedback from the deceased, but then would mention the various responses they get or how they imagine the deceased responding. One person said, 'I don't get feedback. It's more monologue. I picture what he was say."

Just as the communication toward the deceased changes over time, the deceased's feedback has also evolved for some. One man explained, "Mostly now she doesn't talk back anymore. Mostly now, I just occasionally tell her things that I think would make her laugh." Further, one participant indicated that the likelihood of feedback is also determined by a trigger of some sort: "I'm more likely to hear Allen give me feedback if I am there - if I'm at the gravesite; if I'm there. When I'm talking digitally [on Facebook], I'm not expecting feedback. There's no expectation of feedback." 
Further, although many described the feedback they got from the deceased, they rarely expect a response. One mother admitted that she would email or text her deceased son and said, "I am always so sad when it [the email] comes back undeliverable. I know it going to, so sometimes I turn off my phone or computer before I get the message."

\section{Metaphysical}

After showing the initial model of $\mathrm{TcC}$ to the interviewees, some participants indicated that an element of how they conceptualized the communication was missing. They overwhelming agreed that the model illustrates how they view their communication with the deceased, yet many remarked that another "level" was at play. For many, this relied on their religious beliefs; for others, their spiritual or personal beliefs were a factor. One person succinctly stated, "There might be something there that is well beyond us." An interviewee argued, "There should be a little more of an open end to [the TcC model]. It feels a little closed. Because it's not truly just me [participating].” Another explained,

I feel like the communication is sort of open-ended. It's like talking to somebody - it's like there's a wall there and you're talking to a person that may or may not be on the other side of the wall who may or may not give you some feedback. It's not me talking to myself. Talking to the person in the wall. It's not a one-sided conversation to me. That's the best way I can think of it. He's on the other side of the wall. I can't see him. He may or may not be able to see me. He may or may not be able to communicate with me. He may or may not be able to perceive what I'm saying.

One woman explained how a belief in something can positively affect communication with a deceased loved one, "If you believe there's something that survives - whether we call it heart, soul, spirit, whatever - then it's easier to believe that you can talk to these people because 
they're really there on some level of existence." This belief in something led to many participants insisting that the deceased can hear their communication. For example, "I definitely believe that he is listening and hearing everyone's thoughts. It is definitely more of a belief system now. I have to believe that if I talk to him, he hears me." Finally, one person stated, "I think he can hear me. I just can't hear him.”

Some argued that a religious belief system was not a necessary component for communication with the deceased. One man maintained that his own belief is enough, "I think it might be worth making a point that you don't have to be religious/spiritual. I don't need anything to keep some connection with my mother other than my own head. I think that's sufficient." Another interviewee identified a variety of dynamics that could have an effect on how people view communication with the deceased:

The "other something" that I would imagine is entirely just whatever exists in my own head. So my ability to access what is on the other side of that hypothetical wall is really, in my mind, just a reflection of what I've allowed my own head to do. I don't find anything supernatural about that, but I could see how you could. It's like anything metaphysical. There's like half a dozen fun ways that you could imagine: pixies or deities or magic spells or whatever. I just don't go there.

Another agreed and reasoned:

I know there are plenty of scientific explanations for the phenomena I encounter that have nothing to do with Brandon or George speaking to me. Yet, I still strongly believe they are, and it may just be a coping mechanism, but if we get down to it, so is faith and religion. Just because something helps you cope doesn't mean there aren't elements of 
truth to it. You just can't really determine if there is truth because it's not testable by current scientific methods.

As evident from the variety of ways in which the "other something" was described, a specific description of the metaphysical component is elusive. The metaphysical conceptualization appeared to differ from person to person, depending on their religious and spiritual beliefs/non-beliefs.

\section{Transcorporeal Communication and Griefwork}

All participants agreed that their communication with the deceased was a positive experience and an important part of their griefwork. They mentioned that the communication helped them cope with the loss and manage their emotions. One woman said of her grandmother, "By talking to her I feel like I can decompress. I can take all that bottled up stress and talk to someone who understands. Talking to her makes things easier." Many felt that the relational continuity afforded by this communication was of utmost importance, as it allowed them to keep the deceased's memory alive. Examples include: "It means that I don't have to let go. It gives me a sense of relief to talk to her. It makes me feel like I don't have to give her up quite yet," "Talking to my mom is a way for me to maintain a connection as well as cope with her death," and, "It's mostly a comfort thing and just to like maintain contact with him. I think there's part of me that's very scared of forgetting him."

Many people referenced how important this communication is as they got used to physical absence of the deceased. One woman explained,

I'm trying to let go of the emotional pain associated with it while not letting go of the memory. That's where it's difficult. I think it's helping me in terms of its practice of him not being there. So the more that I practice these conversations, keeping it in that safe 
space, the more that I am able to let go of the emotional pain while maintaining the remembrance of who the person was.

Another person summarized,

It's a weird way of finding a new normal I guess. When you love somebody that much and you're so close to somebody, you don't ever want to let them go and so it took me a while to find a way to incorporate him into my life even though he's not here physically. It took a while but now it's just kind of like a thing. It's become a thing that I - it's how I keep in touch with my grandpa. It's a change in communication method more than anything.

Although many researchers view a continued bond and communication with the deceased as a healthy part of grieving, they do offer a warning. People often refer to the deceased in dayto-day life and continue to rely on the dead for advice and might engage in an internal dialogue with the deceased when making decisions (Attig, 1996), which can be beneficial. However, Attig (1996) also argued that these obligations do not (and should not) need to include excessive or constricting actions. Essentially, although people are often influenced by the deceased in their absence, they should not devote themselves excessively.

\section{Discussion: A Model of Transcorporeal Communication}

In response to the first research question, I was able to identify principle elements in the communication between the living and the deceased, resulting in a visual representation of TcC, discussed below. This communication differs from traditional understandings of interpersonal communication in various ways, which is also acknowledged in response to RQ2.

\section{Transcorporeal Communication}


The confirmed model of $\mathrm{TcC}$ is represented in Figure 1. The sender is first triggered to send a message using a variety of means (e.g., speaking aloud, typing) to the inner representation of the deceased. The sender then orients him or herself to the deceased and considers his or her message as he or she believes the deceased would construe it, essentially providing feedback to him or herself based on what he or she believes the receiver (the deceased) would have said.

The inner representation of the deceased comprises a key component of the model of $\mathrm{TcC}$, as the inner representation is the intended recipient of the message and serves as the sender's intended receiver. This imagined presence is closely tied to the deceased's social presence and role as an intended receiver. As previously discussed, the living often integrate the deceased into their life's narrative to regain an understanding of their identities as they exist without the physical presence of the deceased (Marwit \& Klass, 1994-1995). The living accomplish this by creating an inner representation of the deceased and continuing communication with the deceased as a way to cope with the death of their friends and family members. Further, the intensity of the relationship between the participant and the deceased prior to the death likely has an effect on the $\mathrm{TcC}$ that occurs after one party has died. That is, TcC might be less stylized and more idiomatic for a mother who lost her son as compared to a person whose distant relative died.

The concept of feedback is not easily defined within the traditional understanding of how communication functions due to the metaphysical element. Outwardly, the communication occurs within one (living) individual. However, based on the bereaved's religious and/or spiritual beliefs, he or she might argue that they are actually sending messages that the deceased can hear. Correspondingly, the bereaved might then receive what they perceive as messages or feelings from the deceased. 


\section{Comparison to Traditional Communication Models}

Results indicated a unique communication utilized between the living and the deceased not represented in current conceptualizations of communication models. The blueprint of transcorporeal communication looks much like traditional interpersonal communication models However, these traditional models tend to emphasize corporeal communication. That is, the research focuses on the communication that occurs as two parties (each with a physical presence) create and share meanings. When utilizing communication to maintain bonds with the deceased, the individual essentially communicates with the deceased as if the dead person could respond. Since a response from the deceased is impossible, the communication is neither linear nor interactive communication. At the same time, because the individual is sending a message to an intended receiver other than him or herself, the communication is not pure intrapersonal communication (as described by Barker \& Wiseman, 1966).

In Shannon and Weaver's (1949) early, linear model of communication, communication flows in only one direction: from the sender to the intended receiver. The main difference between $\mathrm{TcC}$ and this form of interpersonal communication is that the receiver in the $\mathrm{TcC}$ model does not have a physical body, nor does the receiver have any possibility of providing feedback. Shannon and Weaver described the receiver's responsibility as reconstructing the message from the signal. In the case of $\mathrm{TcC}$, there is no proof that the receiver (the deceased) does decode the message. In fact, it is likely that the sender recognizes the intended receiver's limitation in this area. Knowing this information, the sender nevertheless chooses to encode a message and transmit it to a recipient. This model also implies that only people with physical presences serve as the intended recipients. 
Schramm's (1954) interactive model of communication allowed for a two-way exchange of messages. In this model, the sender transmits a message to the receiver who then provides feedback to the sender. The interactive communication model, posited by Schramm (1954) includes the component of receiver feedback. While feedback is included in TcC, it does not function in the same way as it does in the interactive model. In the interactive model, both the sender and receiver encode and decode messages simultaneously. $\mathrm{In} \mathrm{TcC}$, the receiver (the deceased) does not decode or encode messages.

In transactional communication models, communication is multidirectional, as the parties involved equally influence the communication of the other parties (Barnlund, 1970). As evident, these models of communication involve people who actively participate in the communication process. The transactional communication model appears to be a better fit for describing the communication evident between the living and the dead, but the model fails to account for a communicative situation in which one of the parties involved cannot actively participate nor do they have a physical presence, as is the case when people talk to the deceased.

Imagined interactions (IIs) also appear to be a type of communication similar to that used between the living and the deceased. IIs are a form of daydreaming in which people "rehearse" interactions with other people for future encounters (Honeycutt, 2010; Honeycutt, Zagacki, \& Edwards, 1989). While IIs share similarities with TcC, they are different in one fundamental way. Bereaved people talking to the deceased are not practicing a conversation; rather these people are having a conversation.

\section{Conclusion}

This study represents the first step toward describing the communication between the living and the deceased. Now that this model is established and confirmed, future research 
should explore the relationship between relational satisfaction and frequency of TcC. Perhaps researchers will be able to identify the point of diminishing returns, the point at which $\mathrm{TcC}$ can become an unhealthy behavior (described by Rando, 1992; Raphael, 1983). Additionally, it did not appear that one's spirituality or religious beliefs affected the participant's use of TcC. Externally, it appears that communication occurs exclusively within the grieving individual, "between the bereaved and their cognitive manifestation of the deceased" (described by Egnoto et al., 2014, p. 287). However, many participants insisted that a metaphysical level shaped their understanding of how communication with the deceased was executed. This finding demands additional investigation. Religiousness and spirituality are often glossed over in instances of empirical research, as the presence or influence of a metaphysical "other" are not often directly observable. Future quantitative research could explore the relationship between strength of religious beliefs, use of TcC, and potential health benefits for the bereaved. Related, the next step is also to determine the utility of the TcC model for practitioners. It is also important to note that this model represents the perspective of how those in the Western culture view death and the deceased. Research should also explore how TcC functions (if at all) in other cultures. 


\section{References}

Attig, T. (1996). How we grieve: Relearning the world. New York: Oxford University Press.

Attig, T. (2001). Relearning the world: Making and finding meanings. In R. A. Neimeyer (Ed.), Meaning reconstruction \& the experience of loss (pp. 33-53). Washington, DC: American Psychological Association.

Barker, L. L., \& Wiseman, G. (1966). A model of intrapersonal communication. Journal of Communication, 16, 172-179. doi: 10.1111/j.1460-2466.1966.tb00031.x

Barnlund, D. C. (1970). A transactional model of communication. In K. K. Sereno \& C. D. Mortensen (Eds.), Foundations of communication theory (pp. 83-102). New York: Harper.

Biernacki, P., \& Waldorf, D. (1981). Snowball sampling: Problems and techniques of chain referral sampling. Sociological Methods \& Research, 10(2), 141-163. doi: $10.1177 / 004912418101000205$

Brubaker, J. R., \& Hayes, G. R. (2011, March). “We will never forget you [online] ”: An empirical investigation of post-mortem MySpace comments. Paper presented at Proceedings of the ACM Conference on Computer Supported Cooperative Work, Hangzhou, China. doi:10.1145/1958824.1958843

Davis, C. G., Nolen-Hoeksema, S., \& Larson, J. (1998). Making sense of loss and benefiting from the experience: Two constructs of meaning. Journal of Personality \& Social Psychology, 75, 561-574. doi:http://dx.doi.org/10.1037/0022-3514.75.2.561

de Vries, B. (2001). Grief: Intimacy’s reflection. Generations, 25(2), 75-80.

DeGroot, J. M. (2009). Reconnecting with the dead via Facebook: Examining Transcorporeal Communication as a way to maintain relationships, (Doctoral dissertation, Ohio 
University, 2009). ProQuest Digital Dissertations, AAT 3371475.

DeGroot, J. M. (2012). Maintaining relational continuity with the deceased on Facebook. Omega: Journal of Death and Dying, 65(3), 195-212. doi:http://dx.doi.org/10.2190/OM.65.3.c

Egnoto, M. J., Sirianna, J. M., Ortega, C. R., \& Stefanone, M. (2014). Death on the digital landscape: A preliminary investigation into the grief process and motivations behind participation in the online memoriam. OMEGA: Journal of Death and Dying, 69(3), 283304. doi:http://dx.doi.org/10.2190/OM.69.3.d

Field, N. P., Gal-Oz, E., \& Bonanno, G. A. (2003). Continuing bonds and adjustment at 5 years after the death of a spouse. Journal of Consulting and Clinical Psychology, 71(1), 110117. doi:http://psycnet.apa.org/doi/10.1037/0022-006X.71.1.110

Field, N. P., Nichols, C., Holen, A., \& Horowitz, M. J. (1999). The relation of continuing attachment to adjustment in conjugal bereavement. Journal of Consulting and Clinical Psychology, 67, 212-218. doi:http://dx.doi.org/10.1037/0022-006X.67.2.212

Glick, I. O., Weiss, R. S., \& Parkes, C. M. (1974). The first year of bereavement. New York: John Wiley, Interscience.

Hallam, E., Hockey, J., \& Howarth, G. (1999). Beyond the body: Death and social identity. London: Routledge.

Hastings, S. O., Hoover, J. D., Musambira, G. W. (2005). "In my heart for eternity": Normalizing messages to the deceased. Storytelling, Self, Society, 1(2), 11-25. doi:10.1080/15505340509490263

Hofer, M. A. (1984). Relationships as regulators: A psychobiologic perspective on bereavement. Psychosomatic Medicine, 46, 183-197. 
Honeycutt, J. M. (2010). Introduction. In Honeycutt, J. M. (Ed.). Imagine that: Studies in imagined interaction (pp. 1-14). Creskill, NJ: Hampton Press, Inc.

Honeycutt, J. M., Zagacki, K. S., \& Edwards, R. (1989). Intrapersonal communication, social cognition, and imagined interactions. In C. V. Roberts \& K. W. Watson (Eds.), Intrapersonal communication processes (pp. 166-184). Scottsdale, AZ: Gorsuch Scarisbrick.

Jackson, E. N. (1957). Understanding grief: Its roots, dynamics, and treatment. New York, NY: Abingdon Press.

Klass, D. (1993). Solace and immortality: Bereaved parents' continuing bond with their children. Death Studies, 17(4), 343-368. doi:10.1080/07481189308252630

Klass, D., Silverman, P. R., \& Nickman, S. L. (Eds.). (1996). Continuing bonds: New understandings of grief. Washington, DC: Taylor \& Francis.

Klass, D., \& Walter, T. (2001). Processes of grieving: How bonds are continued. In M. S. Stroebe, R. O. Hansson, W. Stroebe, \& H. Schut (Eds.), Handbook of bereavement research (pp. 431-448). Washington, DC: American Psychological Association.

Lincoln, Y., \& Guba, E. (1985). Naturalistic inquiry. Beverly Hills, CA: Sage Publications. Marwit, S. J., \& Klass, D. (1994-1995). Grief and the role of the inner representation of the deceased. Omega: Journal of Death and Dying, 30(4), 283-298. doi:10.2190/PEAAP5AK-L6T8-5700

Mitchell, M. (2007). Constructing immortality: The role of the dead in everyday life. In M. Mitchell (Ed.), Remember me (pp. 1-18). New York: Routledge.

Parkes, C. M. (1970). “Seeking” and "finding” a lost object: Evidence from recent studies of reaction to bereavement. Social Science and Medicine, 4, 187-201. 
Pennington, N. (2013). You don't de-friend the dead: An analysis of grief communication by college students through Facebook profiles. Death Studies, 37, 617-635. doi:10.1080/07481187.2012673536

Rando, T. A. (1986). Parental loss of a child. Champaign, IL: Research Press.

Rando, T. A. (1992). The increasing prevalence of complicated mourning: The onslaught is just the beginning. OMEGA: Journal of Death and Dying, 26(1), 43-59. doi:10.2190/7MDLRJTF-NA2D-NPQF

Raphael, B. (1983). The anatomy of bereavement. New York: Basic Books.

Rees, W. D. (1971). The hallucinations of widowhood. British Medical Journal, 4, 37-41. doi:http://dx.doi.org/10.1136/bmj.4.5778.37

Rubin, S. S. (1985). The resolution of bereavement: A clinical focus on the relationship to the deceased. Psychotherapy, 22(2), 231-235. doi:http://dx.doi.org/10.1037/h0085499

Schramm, W. (1954). The process and effects of mass communication. Urbana: University of Illinois Press.

Shuchter, S. R., \& Zisook, S. (1993). The course of normal grief. In M. S. Stroebe, W. Stroebe, \& R. O. Hansson (Eds.), Handbook of bereavement: Theory, research, and intervention (pp. 102-111). New York: Cambridge University Press.

Silverman, P., \& Klass, D. (1996). Introduction: What's the problem? In D. Klass, P. Silverman, \& S. Nickman (Eds.), Continuing bonds: New understandings of grief (pp. 73-86). Washington, DC: American Psychological Association Press.

Stroebe, M., \& Schut, H. (1999). The dual process model of coping with bereavement: Rationale and description. Death Studies, 23, 197-224. doi:10.1080/074811899201046 
Weiss, R. S. (1993). Loss and recovery. In M. S. Stroebe, W. Stroebe, \& R. O. Hansson (Eds.), Handbook of bereavement: Theory, research, and intervention (pp. 102-111). New York: Cambridge University Press. 
Table 1

\section{Participant Information}

\begin{tabular}{|c|c|c|c|c|c|c|c|c|c|c|}
\hline Participant & Sex & $\begin{array}{l}\text { Age } \\
\text { (yrs) }\end{array}$ & $\begin{array}{l}\text { Religious/ } \\
\text { Spiritual } \\
\end{array}$ & Deceased & $\begin{array}{l}\text { Relation to } \\
\text { Participant }\end{array}$ & Sex & $\begin{array}{l}\text { Age at } \\
\text { Death } \\
\text { (yrs) }\end{array}$ & $\begin{array}{l}\text { Cause of } \\
\text { Death }\end{array}$ & $\begin{array}{l}\text { Years } \\
\text { since } \\
\text { Death } \\
\end{array}$ & $\begin{array}{l}\text { Type of } \\
\text { Interview }\end{array}$ \\
\hline Michael & $\mathrm{M}$ & 37 & Spiritual & Allen & Brother & $\mathrm{M}$ & 32 & Cancer & 0.75 & Skype \\
\hline Elizabeth & $\mathrm{F}$ & 64 & Religious & Rourke & Son & M & 13 & Unknown & 16 & Skype \\
\hline Christina & $\mathrm{F}$ & 34 & Spiritual & Elwood & Grandfather & M & 86 & Heart attack & 10 & Skype \\
\hline \multirow[t]{2}{*}{ Renee } & $\mathrm{F}$ & 31 & Religious & Gram & $\begin{array}{l}\text { Great } \\
\text { Grandmother }\end{array}$ & $\mathrm{F}$ & 97 & Health issues & 3.5 & Skype \\
\hline & & & & Jen & $\begin{array}{l}\text { Great } \\
\text { Grandmother }\end{array}$ & $\mathrm{F}$ & 95 & Health issues & 1.17 & \\
\hline Anne & $\mathrm{F}$ & 53 & Religious & Thomas & Son & $\mathrm{M}$ & 21 & Car accident & 12 & Email \\
\hline \multirow[t]{2}{*}{ Vickie } & $\mathrm{F}$ & 26 & Both & George & Uncle & $\mathrm{M}$ & 53 & $\begin{array}{l}\text { Health issues } \\
\text { after broken } \\
\text { leg }\end{array}$ & 14 & Email \\
\hline & & & & Brandon & Ex-boyfriend & $\mathrm{M}$ & 27 & $\begin{array}{l}\text { Gunshot } \\
\text { wound }\end{array}$ & 3 & \\
\hline Laura & $\mathrm{F}$ & 23 & Religious & Cassie & HS classmate & $\mathrm{F}$ & 17 & Cancer & 6 & Email \\
\hline Justin & $\mathrm{M}$ & 53 & Atheist & Lorelei & Mother & $\mathrm{F}$ & 52 & Cancer & 26 & Skype \\
\hline Ashley & $\mathrm{F}$ & 20 & Religious & Jimmy & Dad & $\mathrm{M}$ & 35 & Cancer & 10 & Email \\
\hline Charlotte & $\mathrm{F}$ & 42 & Religious & Gabe & Infant son & $\mathrm{M}$ & 0 & $\begin{array}{l}\text { Health } \\
\text { complications } \\
\text { from Down } \\
\text { Syndrome }\end{array}$ & 7 & Email \\
\hline Beth & $\mathrm{F}$ & 39 & Spiritual & Frank & Dad & $\mathrm{M}$ & 74 & $\begin{array}{l}\text { Wegener's } \\
\text { disease }\end{array}$ & 0.58 & Skype \\
\hline Jessica & $\mathrm{F}$ & 30 & Spiritual & Doris & Grandmother & $F$ & 90 & $\begin{array}{l}\text { Natural } \\
\text { causes }\end{array}$ & 1 & Email \\
\hline Taylor & $\mathrm{M}$ & 36 & Spiritual & Debbie & Mother & $\mathrm{F}$ & 62 & Lung cancer & 5 & Skype \\
\hline Jackie & $\mathrm{F}$ & 19 & No & David & HS classmate & $\mathrm{M}$ & 18 & Car accident & 2 & Email \\
\hline Meredith & $\mathrm{F}$ & 31 & $\begin{array}{l}\text { Spiritual; } \\
\text { somewhat } \\
\text { religious }\end{array}$ & Mary & Mother & $\mathrm{F}$ & 43 & ATV accident & 19 & Email \\
\hline Joanne & $\mathrm{F}$ & 65 & Religious & Clark & Husband & $\mathrm{M}$ & 64 & Pneumonia & 0.17 & Email \\
\hline Nancy & $\mathrm{F}$ & 67 & No & Neil & Husband & $\mathrm{M}$ & 76 & Heart attack & 0.08 & Email \\
\hline Courtney & $\mathrm{F}$ & 23 & Religious & Leigh & HS Friend & $\mathrm{F}$ & 18 & Leukemia & 5 & Email \\
\hline Kyle & $\mathrm{M}$ & 40 & Religious & William & Dad & $\mathrm{M}$ & 60 & Cancer & 7 & Email \\
\hline Adam & $\mathrm{M}$ & 50 & $\begin{array}{l}\text { Slightly } \\
\text { Spiritual } \\
\end{array}$ & Brenda & Mother & $\mathrm{F}$ & 69 & $\begin{array}{l}\text { Congestive } \\
\text { heart disease }\end{array}$ & 3 & Email \\
\hline
\end{tabular}

Notes. Pseudonyms are used for both the participant and deceased. Renee and Vickie discussed

two deceased individuals. 
Figure 1. Model of Transcorporeal Communication

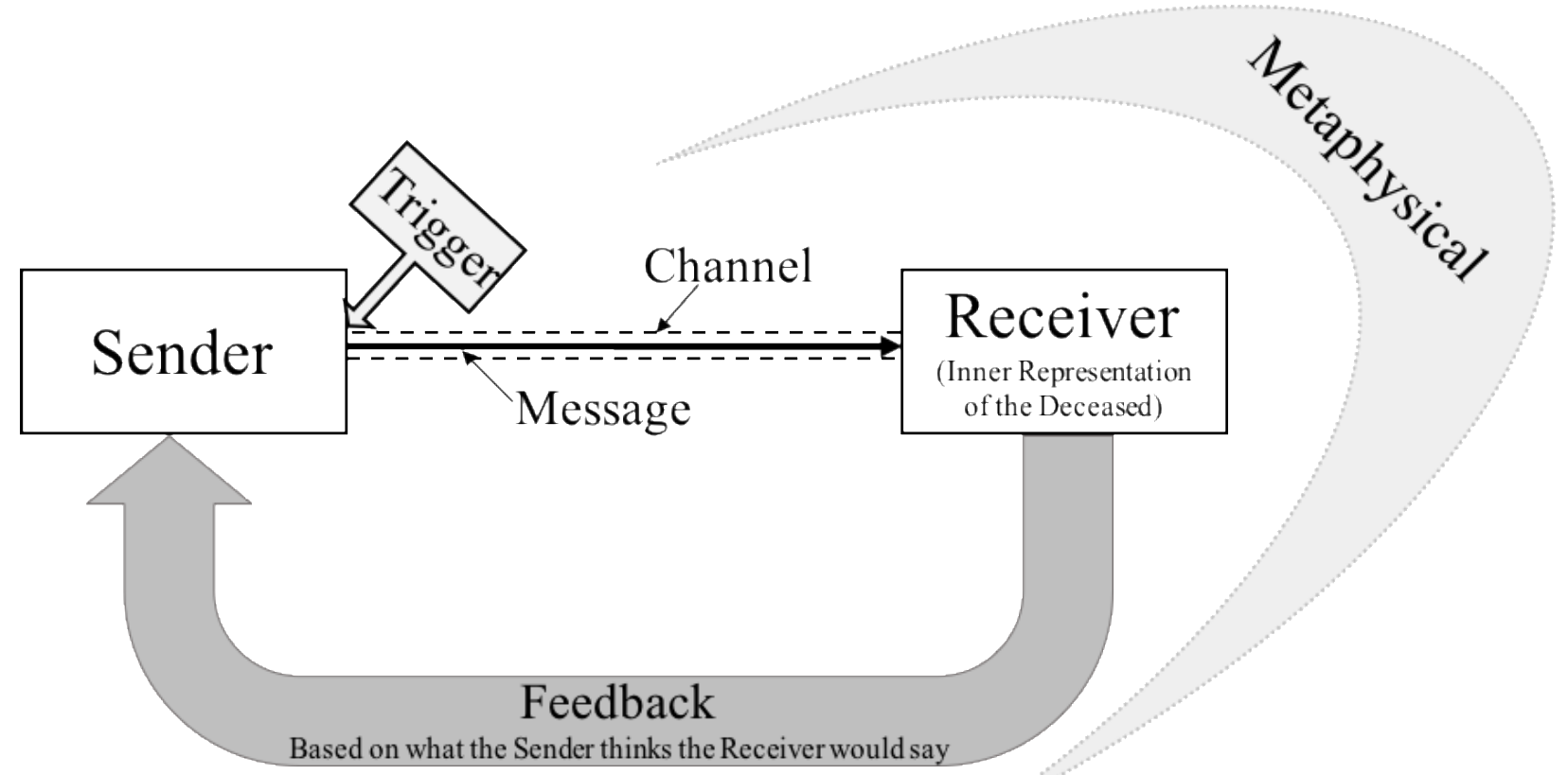

